\title{
Influence of hydrolysis on the mechanical properties of PLA nanofibers
}

\author{
K. Tanaka, M. Ono \& T. Katayama \\ Department of Biomedical Engineering, Doshisha University, Japan
}

\begin{abstract}
Due to the high surface area to volume ratio, polymer nanofibers are expected to be used for a wide range of applications such as tissue engineering, drug delivery, wound dressing scaffolds, artificial blood vessels and so on.

Poly L-lactic acid (PLLA) is a thermoplastic resin with a melting temperature of about $180^{\circ} \mathrm{C}$. Its melting temperature is not high enough in some applications. An equimolar mixture of poly L-lactic acid (PLLA) and poly D-lactic acid (PDLA) can be crystallized into a stereocomplex-type PLA (SCPLA). The melting point of a stereocomplex crystal is $50^{\circ} \mathrm{C}$ higher than that of PLLA. It has been reported that SCPLA is more stable against hydrolysis than PLLA.

Poly lactic acid (PLA) is one of a few polymers that are practically applied as various medical materials such as implants and sutures. Since PLA is easily hydrolyzed in a water environment, the effect of water absorption on the mechanical properties should be investigated.

In this study, the influence of hydrolysis on the mechanical properties of PLLA and SCPLA nanofiber were investigated by a single nanofiber tensile test. The tensile strengths of PLLA and SCPLA nanofiber were $141 \mathrm{MPa}$ and $165 \mathrm{MPa}$, respectively. The immersing in water at $37^{\circ} \mathrm{C}$ for 4 weeks does not affect the mechanical properties of either PLLA or SCPLA.

Keywords: electrospinning, nanofiber, poly L-lactic acid (PLA), tensile test, stereocomplex-type PLA, hydrolysis.
\end{abstract}

\section{Introduction}

Polymer nanofibers are attractive materials for a wide range of applications because of their large surface area to volume ratio and unique nanometer scale architecture. Due to the high-affinity for cell, nanofibers are expected to be used 
for wide applications in the medical field, such as tissue engineering scaffolds, drug delivery carriers, biosensors, molecular filtration membranes, highly functional clothes and so on [1-7].

An electrospinning technique is a simple method for the production of nanofibers. In this technique, a polymer solution is blown out from a needle hole, while an electric field is applied between a polymer solution and a target. During the electrospinning process, the solvent evaporates and polymer nanofibers are fabricated on the target $[3,8,9]$.

Poly L-lactic acid (PLLA) is a thermoplastic resin with a melting temperature of about $180^{\circ} \mathrm{C}$ [7]. Although this melting temperature is fairly high compared to the other biodegradable polymers, its melting temperature is not high enough in some applications $[10,11]$. An equimolar mixture of poly L-lactic acid (PLLA) and poly D-lactic acid (PDLA) can be crystallized into a stereocomplex-type PLA (SCPLA) [12-14]. The melting point of stereocomplex crystal is $50^{\circ} \mathrm{C}$ higher than that of PLLA [13]. Furthermore, it has been reported that SCPLA is more stable against hydrolysis than PLLA [2, 7].

Poly lactic acid (PLA) is one of the few polymers that is practically applied in various medical materials such as implants and sutures [15]. The reduction of mechanical properties by biodegradation cannot be avoided. Thus it is significant to clarify the influence of hydrolysis on the mechanical properties of PLA nanofibers [16]. Due to the difficulty in handling individual nanofibers, hydrolysis of single nanofibers have not been clarified yet.

In this study, to understand the influence of hydrolysis on the mechanical properties of PLLA and SCPLA nanofibers, the nanofibers that spun by electrospinning were immersed in distilled water at $37^{\circ} \mathrm{C}$ for 4 weeks. Tensile tests were performed for dry and wet specimens.

\section{Experimental}

\subsection{Materials and method}

PLLA and SCPLA were used in this study. The PLLA (weight-average molecular-weight, $\mathrm{Mw}=2.7 \times 105 \mathrm{~g} / \mathrm{mol})$ and PDLA $(\mathrm{Mw}=1.8 \times 105 \mathrm{~g} / \mathrm{mol})$ were blended (PLLA/PDLA $=1: 1)$. Two kinds of solvents were mixed at different concentration. DCM (DCM: dichloromethane) is used for solvent purpose and DMF (DMF: dimethylformamide) was added to control solution conductivity. It is known that higher solution conductivity results in the formation of nanofibers with less beads and smaller diameters. DMF has a dielectric constant of 37, whereas DCM has a dielectric constant of 8.9. Polymer was first dissolved in DCM before DMF was added. The nanofibers were fabricated from 8 wt\% polymer solution with DCM and DMF in the ratio of 8:2 $(\mathrm{w} / \mathrm{w})$ as the solvent. Nanofibers were fabricated using Nanofiber Electrospinning Unit (NEU, Kato Tech) shown in Fig. 1. Electrospinning was conducted at room temperature $\left(15 \pm 3^{\circ} \mathrm{C}\right)$, with relative humidity at $35-40 \%$. An applied voltage was set for $15 \mathrm{kV}$ between the needle for polymer solution and the target with a flow rate of polymer solution of $3.0 \times 10^{-4} \mathrm{ml} / \mathrm{sec}$. PLLA and 
SCPLA nonwoven nanofiber was spun on the collector of aluminum foil and single nanofiber was spun on the collector of $\mathrm{Cu}$ strips. To fabricate aligned single nanofibers for the tensile test, two $\mathrm{Cu}$ strips which were placed parallel with $30 \mathrm{~mm}$ distance were used for target (as shown in Fig. 2). Circuit and electrodes were placed as shown in Fig. 3. The electrical potentials difference between two $\mathrm{Cu}$ strips was set at $3 \mathrm{~V}$. Some specimens of PLLA and SCPLA nanofibers were immersed in distilled water at $37^{\circ} \mathrm{C}$, which will be called as wet specimens, and they were removed after immersed in water for 4 weeks. Tensile test was performed for dry and wet specimens. SCPLA and PLLA nanofibers were not immersed in water are called SCPLA0h and PLLA0h respectively. SCPLA and PLLA nanofibers immersed in water for 4 week are called SCPLA4W and PLLA4W respectively.

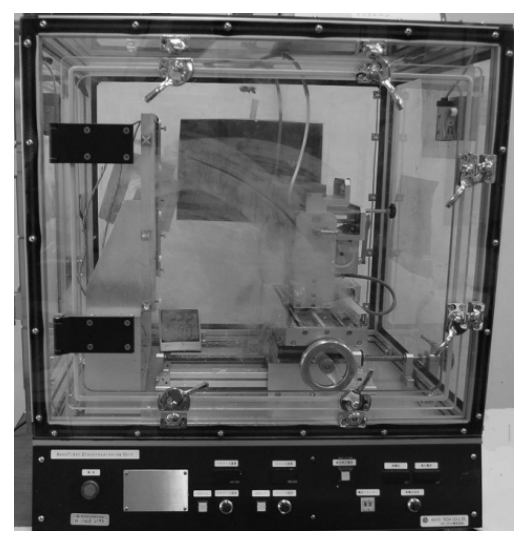

Figure 1: $\quad$ Nanofiber electrospinning unit.

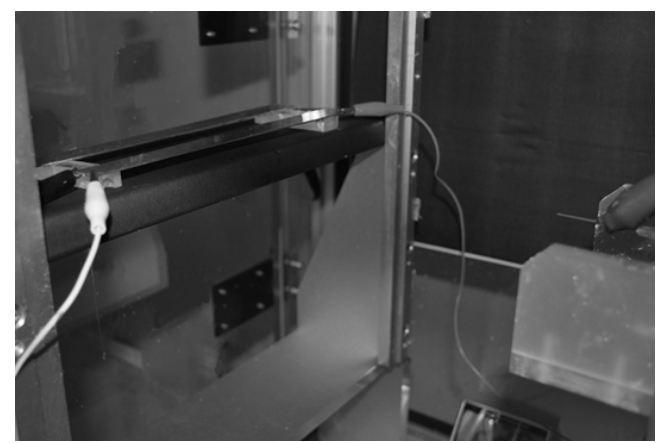

Figure 2: $\quad$ Device for fabrication of aligned single nanofibers. 


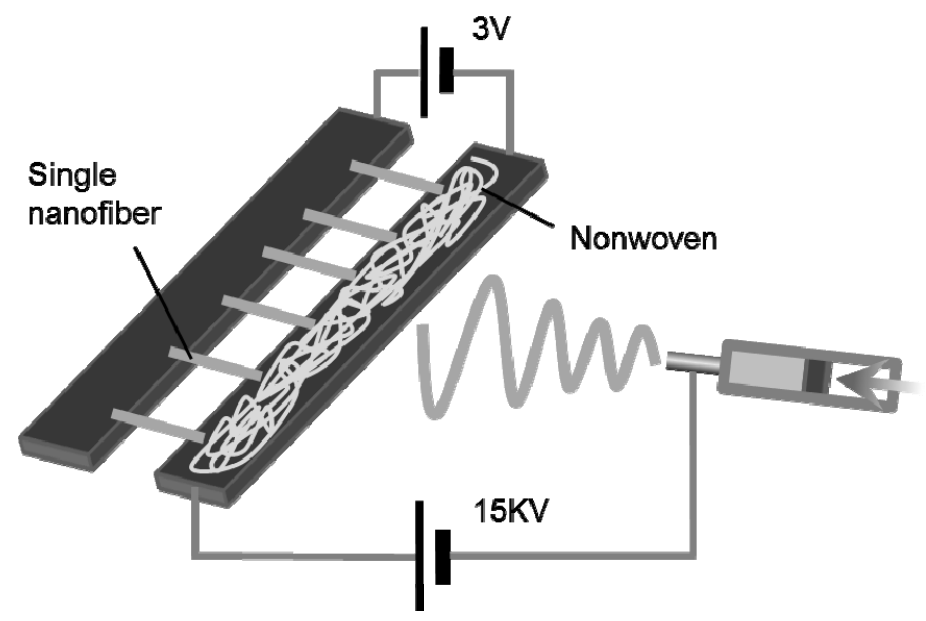

Figure 3: $\quad$ Schematic drawing of fabrication of aligned single nanofibers.

\subsection{Mechanical properties}

Scanning electron microscopy (SEM, JSM-6390LT, JEOL), were used to investigate the structure and morphology of the electrospun PLLA and SCPLA nanofibers for dry and wet specimens. Differential scanning calorimetry analyses were performed in order to assess changes in the crystallization behavior of PLLA4W and SCPLA4W nanofibers after hydrolysis. DSC analyses were performed on a Differential scanning calorimeter (DSC, DSC-60, SHIMADZU). The samples (2 mg) were ramped from room temperature to $300^{\circ} \mathrm{C}$, isothermal for $2 \mathrm{~min}$, and then ramped down to $25^{\circ} \mathrm{C}$. The scanning rate was set for $10^{\circ} \mathrm{C} / \mathrm{min}$.

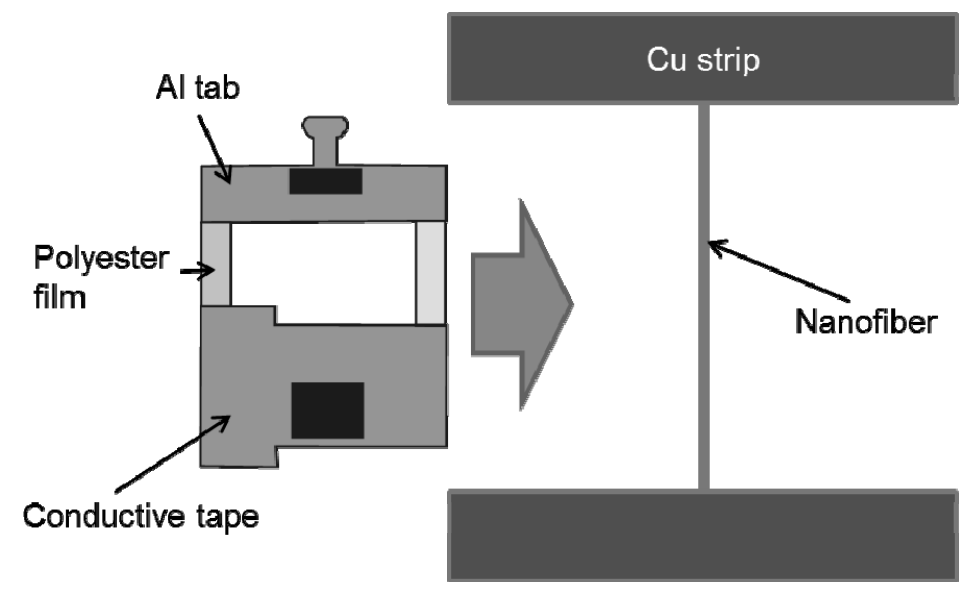

Figure 4: $\quad$ Procedure of specimen preparation. 
Specimens for tensile test were prepared by using aligned single nanofibers. On an Al tab, a single nanofiber was glued with conductive tapes (as shown in Fig. 4). The tensile tests of nanofibers for dry and wet specimens were conducted using a nano tensile testing machine (NanoTensile, Hysitron), at a displacement rate of $10 \mu \mathrm{m} / \mathrm{s}(0.6 \mathrm{~mm} / \mathrm{min})$. This testing machine has $500 \mathrm{mN}$ load range and $12.5 \mathrm{nN}$ load resolution. After tensile test, the diameter of nanofiber which bonded to conductive tape was measured using the SEM. The average value of diameter at five points was used to calculate the tensile strength.

\section{Result and discussion}

\subsection{Morphology}

The SEM images of the PLLA0h and SCPLA0h nonwoven nanofibers are shown in Fig. 5. A noticeable change in fiber uniformity didn't observed. The average fiber diameter of PLLA0h nanofibers was $490 \pm 90 \mathrm{~nm}$ based on an average of 20 fibers, while that of the SCPLA0h was $440 \pm 70 \mathrm{~nm}$. The SEM images of the PLLA4W and SCPLA4W nonwoven nanofibers are shown in Fig. 6. The surface

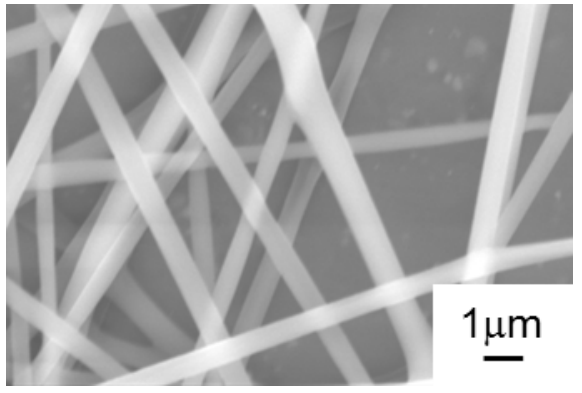

(a) PLLA0h.

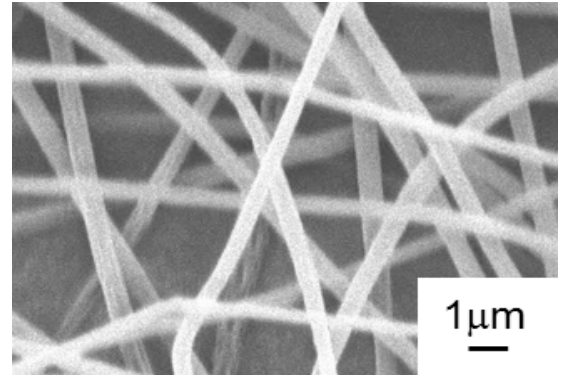

(b) SCPLA0h.

Figure 5: $\quad$ SEM images of nonwoven nanofibers.

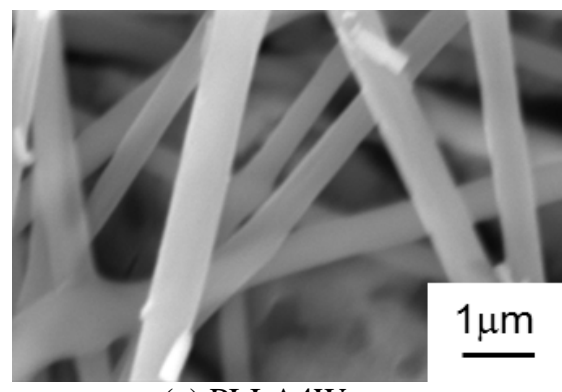

(a) PLLA4W.

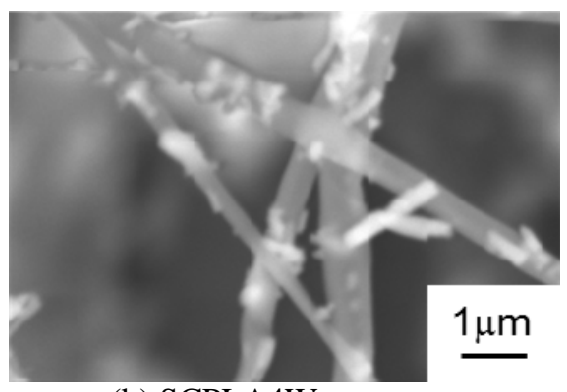

(b) SCPLA4W.

Figure 6: SEM images of nonwoven nanofibers after immersion in distilled water for 4 weeks. 
of both the PLLA4W and SCPLA4W was partially covered with accretions, but erosion was not observed on the surface of both nanofibers.

\subsection{Tensile test}

A typical stress-strain curve of single electrospun PLLA nanofiber is shown in Fig. 7. After elastic deformation, large plastic deformation was observed. For SCPLA nanofibers, similar behavior was observed. The tensile strengths are shown in Fig 8. The tensile strength of SCPLA0h nanofibers was $165 \pm 14 \mathrm{MPa}$, while that of the SCPLA4W was $156 \pm 39 \mathrm{MPa}$. The tensile strength of PLLA0h nanofibers was $141 \pm 19 \mathrm{MPa}$, while that of the PLLA4W was $137 \pm 16 \mathrm{MPa}$. The immersing in water at $37^{\circ} \mathrm{C}$ for 4 weeks does not effect on the mechanical properties of both PLLA and SCPLA.

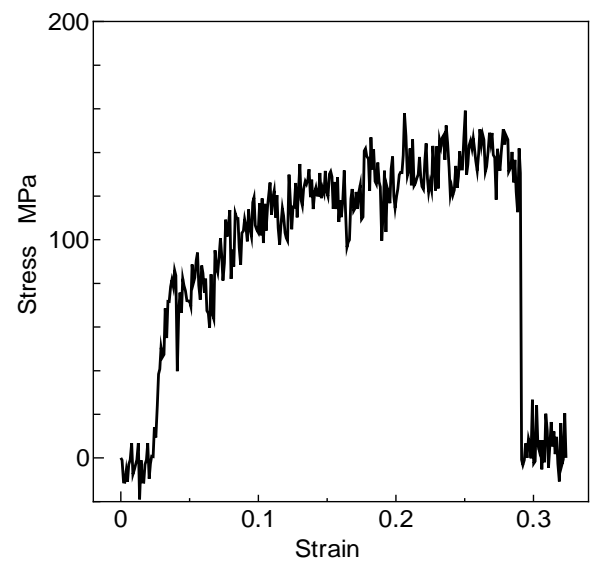

Figure 7: Example of a stress-strain curve for a single electrospun nanofiber (PLLA0h).

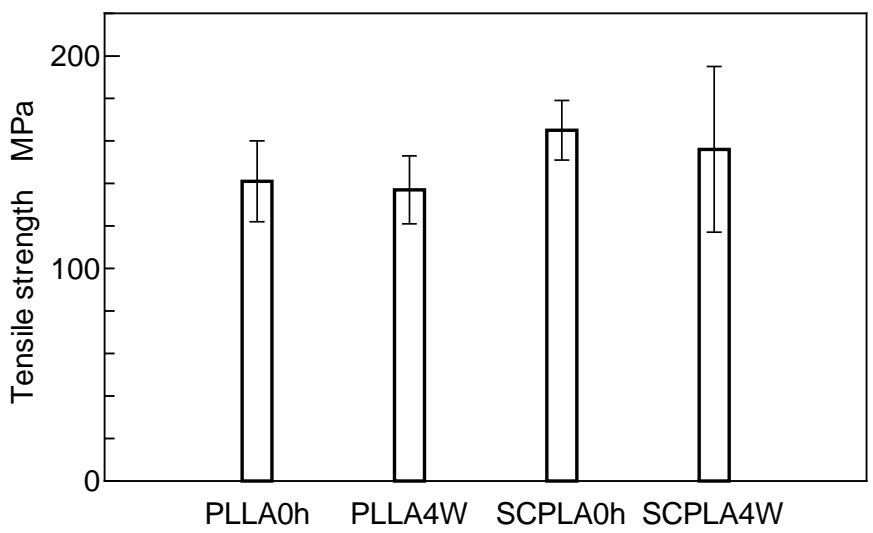

Figure 8: The tensile strength for PLLA and SCPLA of dry and wet specimens. 


\subsection{Thermal analysis}

To evaluate the influence of hydrolysis on the crystalline structure of nanofibers, DSC analyses on the PLLA and SCPLA nanofibers for dry and wet specimens were conducted. The heating curves are presented in Figs. 9. The quantitative results of the DSC curves are tabulated in Table 1 where the onset melting temperature and crystallinity values are listed. The melting points $\left(\mathrm{T}_{\mathrm{m}}\right)$ of the PLLA0h and SCPLA0h nanofibers were recorded at $173^{\circ} \mathrm{C}$ and $216^{\circ} \mathrm{C}$, respectively. The higher $T_{m}$ of the SCPLA nanofibers indicates the presence of stereocomplex crystals formed during the electrospinning process. The crystallinity values of the PLLA0h and SCPLAOh nanofibers were recorded at $47 \%$ and $37 \%$, respectively. The crystallinity values of the PLLA4W and SCPLA4W nanofibers were recorded at $27 \%$ and $31 \%$, respectively. The immersing in water had significant effects on the crystalline structure of PLLA nanofibers. In SCPLA nanofibers the decrease in crystallinity values for SCPLA

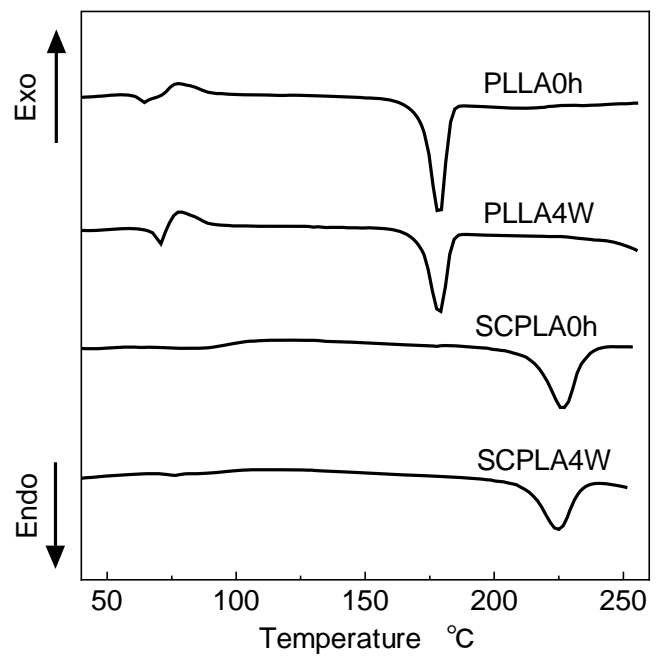

Figure 9: The heating curves for PLLA and SCPLA nanofibers of dry and wet specimens.

Table 1: The corresponding thermal properties of PLLA and SCPLA nanofibers dry and wet specimens.

\begin{tabular}{|l|c|c|}
\hline & $\mathrm{T}_{\mathrm{m}}\left({ }^{\circ} \mathrm{C}\right)$ & Crystallinity values (\%) \\
\hline PLLA0h & 173 & 47 \\
\hline PLLA4W & 172 & 27 \\
\hline SCPLA0h & 216 & 37 \\
\hline SCPLA4W & 214 & 31 \\
\hline
\end{tabular}


was not as significant as PLLA. This suggests that the hydrolysis by water is only high enough to induce chain scission in crystalline structure of PLLA and is inadequate to cause damage to the crystalline structure of SCPLA.

\section{Conclusions}

In this study, to understand the influence of hydrolysis on the mechanical properties of PLA nanofibers, tensile test was performed for PLLA and SCPLA nanofibers for dry and wet specimens. DSC analyses on the PLLA and SCPLA nanofibers for dry and wet specimens were conducted. The investigation yielded the following conclusions.

1. The tensile strength of PLLA0h and SCPLA0h nanofiber were $141 \mathrm{MPa}$ and 165MPa respectively. The tensile strength of PLLA4W and SCPLA4W nanofiber were $137 \mathrm{MPa}$ and $156 \mathrm{MPa}$ respectively. The immersing in water at $37^{\circ} \mathrm{C}$ for 4 weeks does not affect on the mechanical properties of both PLLA and SCPLA.

2. The crystallinity values of the PLLA0h and SCPLA0h nanofibers were recorded at $47 \%$ and $37 \%$ respectively. The crystallinity values of the PLLA4W and SCPLA4W nanofibers were recorded at $27 \%$ and $31 \%$ respectively. This suggests that the hydrolysis by water is only high enough to induce chain scission in crystalline structure of PLLA and it is inadequate to cause damage to the crystalline structure of SCPLA.

\section{References}

[1] Ramakrishna, S., Fujihara, K., Teo, W. E., Yong, T., Ma, Z., Ramaseshan, R., Electrospun nanofibers: solving global issues, Materials today, 9(3), pp. 40-50, 2006.

[2] Tanioka, A., Kawaguchi, T., Frontline in Commercialization Technologies and Development of Applications on Nanofibers, CMC publication, pp. 150, 2012.

[3] Li, D, Frey, W. M., Baeumner, J. A., Electrospun polylactic acid nanofiber membranes as substrates for biosensor assemblies, Journal of Membrane Science, 279, pp. 354-363, 2006.

[4] Shokyu, G., Polylactic acid as medical fiber, Dyeing Research, 54(5), pp. 70-75, 2006.

[5] Shin, M., Yoshimoto, H., Vacanti, P. J., In vivo Bone Tissue Engineering Using Mesenchymal Stem Cells on a Novel Electrospun Nanofibrous Scaffold, Tissue Engineering, 10(1/2), pp. 33-41, 2004.

[6] Caixeta, A., Lansky, J. A., Serruys, W. P., Hermiller, B. J., Clinical FollowUp 3 Years After Everolimus- and Pacliraxel-Eluting Stents, Cardiovascular Interventions, 3(12), pp. 1220-1228, 2010.

[7] Yamane, H., New Developments of Poly (lactic Acid), Journal of the Society of Materials Science, Japan, 56(10), pp. 993-997, 2010. 
[8] Tanioka, A., Fabrication and application of nano-fibers, Proceedings of the Conference on the Science Council of Japan Federation of Materials Science and Engineering, 53, pp. 1-4, 2009.

[9] Yamashita, Y., Forefront of electrospinning, Publication of Fiber Company Planning, pp. 1-93, 2007.

[10] Murase, S., Mochizuki, M., Poly (lactic acid) Fiber- Environmentally Friendly New Generation Fiber Made from Plant-, Sen'I Gakkaishi, 54(6), pp. 323-329, 2006.

[11] Takahashi, H., Polylactic acid Fiber, Industrial Material, 54(1), pp. 60-61, 2006.

[12] Anderson, S.K., Hillmyer, A.M., Melt preparation and nucleation efficiency of polylactide stereocomplex crystallites, Polymer, 47, pp. 2030-2035, 2006.

[13] Toyohara, T., Tokawa, K., Kimura, Y., Stereocomplex polylactic acid type - High heat-resistant lactic acid based bioplastics - Fine chemical, 36(2), pp. 39-45, 2007.

[14] Ikada, Y., Jamshidi, K., Tsuji, H., Hyon, H.S., Stereocomplex formation between enantiomeric poly(lactides), Macromolecules, 20(4), pp. 904-906, 1987.

[15] Marler, J. J., Upton, J., Langer, R., Vacanti, P. J., Transplantation of cells in matrices for tissue regeneration, Advanced Drug Delivery Reviews, 33, pp. 165-182, 1998.

[16] Ishii, D., Ying, H. T., Mahara, A., Murakami, S., Yamaoka, T., Lee, W. K., and Iwata, T., In Vivo Tissue Response and Degradation Behavior of PLLA and Stereocomplexed PLA Nanofibers, Biomacromolecules, 10, pp. 237242, 2009. 